\title{
EDITORIAL
}

\section{Is breast cancer a part of Lynch syndrome?}

\author{
James M Ford* \\ See related research by Lotsari et al., http://breast-cancer-research.com/content/14/3/R90
}

\begin{abstract}
A long-standing question is whether breast cancer is an integral part of Lynch syndrome, also known as hereditary non-polyposis colorectal cancer. A recent study by Lotsari and colleagues analyzes molecular features of breast cancers from families with Lynch syndrome, including germline mutation carriers and their non-mutation carrier siblings, and controls with sporadic breast cancer. The study finds microsatellite instability and loss of mismatch DNA repair protein expression in one third and two thirds of Lynch syndrome samples, respectively, but in none of the non-mutation carriers or controls. Overall, the age of diagnosis of breast cancer in Lynch syndrome mutation carriers is no different than that in noncarriers, but diagnosis age was lower in those carriers whose breast tumors exhibited defects in mismatch repair. These results have important implications for genetic counseling and genetic testing of families with breast cancer and other tumors associated with Lynch syndrome, such as colorectal and endometrial cancers.
\end{abstract}

In a comprehensive analysis of all available breast cancers from among 200 Lynch syndrome (LS) families in a nationwide registry in Finland, Lotsari and colleagues [1] address the question of whether breast cancer is an integral part of LS. The results, published in the previous issue of Breast Cancer Research, are compelling and could inform the way we conduct genetic testing in the diagnosis of LS and set guidelines for breast cancer surveillance in LS mutation carriers.

A central tenet in cancer biology is that most human tumors are associated with, and often are caused by, abnormally elevated levels of genomic instability due to inherited or sporadically acquired defects in DNA repair mechanisms [2]. Although the comprehensiveness of this

*Correspondence: jmf@stanford.edu

Department of Medicine (Oncology), Stanford University School of Medicine, Room 1115, CCSR Building, 269 Campus Drive, Stanford, CA 94305-5151, USA hypothesis is vigorously argued in the literature, LS (also known as hereditary non-polyposis colorectal cancer) is considered a paradigm for the mutator phenotype $[3,4]$. An autosomal dominant Mendelian disorder caused by heterozygous germline mutations in one of four DNA mismatch repair (MMR) genes [5], tumors arising in LS mutation carriers usually undergo loss-of-heterozygosity in the corresponding normal MMR gene, typically resulting in loss of protein expression as assessed by immunohistochemistry (IHC), and exhibit an MMR functional deficiency as defined by the presence of microsatellite instability (MSI) [6]. Therefore, a set of readily available phenotypic assays (MSI and IHC for MMR proteins) can help identify underlying genomic instability and guide germline genetic testing to the appropriate causative allele, thereby greatly facilitating screening [7]. In addition to the two most common cancers that define LS (colorectal and endometrial cancer), a spectrum of malignancies - ovarian, stomach, small bowel, hepatobiliary, ureteral tract, pancreas, skin, brain, and others - has been associated with LS on the basis of their increased incidence in MMR gene mutation carriers and more recently on the basis of documented molecular phenotyping and genotyping of the tumors themselves.

Whether breast cancer is a component of LS has been debated since the latter was first suggested by Henry Lynch [8]. Beyond just an academic question, this issue is of importance for guiding genetic counseling and diagnostic testing of families with a history of breast cancer in addition to other LS-associated tumors, for screening surveillance and clinical management of breast cancer risk in LS, and potentially by providing prognostic or predictive information (or both). Both the revised Amsterdam criteria for diagnosis of LS [9] and the revised Bethesda criteria for identification of individuals for MSI testing [10] take into account extracolonic tumors but not breast cancer. Several studies have suggested an elevated risk for breast cancer in LS, but the issue remains controversial. Most studies are limited by being small, retrospective, and lacking in statistical power. More recently, molecular studies have been added to the epidemiologic approach. MSI is very rare $(0 \%$ to $3 \%$ of cases) in sporadic breast cancer [11] but is observed in more than half of breast cancer cases diagnosed in LS 
mutation carriers [12,13]. Most recently, a prospective study of cancer risk in $446 \mathrm{MMR}$ gene mutation carriers compared with 1,029 non-carrier relatives ascertained from the Colon Cancer Family Registry found a fourfold increased risk for breast cancer [14], although whether the age of diagnosis was younger in these seven cases could not be determined.

In this context comes the study by Latsari and colleagues [1]. In hopes of advancing the understanding of breast cancer as a possible tumor in the LS spectrum and the role of MSI in breast cancer tumorigenesis, the authors identify and study all cases of LS-associated breast cancer in the Finish Hereditary Colorectal Cancer Registry. In this well-designed and controlled study, MSI and IHC for the MMR proteins MLH1, MSH2, and MSH6 were performed on 23 breast cancers from 19 LS patients with known germline mutations, 18 breast cancers from 18 known non-mutation carriers from LS families, and 49 sporadic breast cancers from non-LS families and were presented together with detailed information on the tumor pathology and patient age at diagnosis. The results are quite interesting. MMR pathway defects were clearly associated with breast cancers from LS patients but were more frequently associated with other accepted extracolonic LSassociated tumors studied; approximately two thirds of the 23 breast cancers with germline LS mutations exhibited loss of MMR protein expression and only half of these exhibited MSI, but no LS non-mutation carriers or sporadic controls exhibited MMR defects. A closer look at the heterogeneity in MMR activity in LSassociated breast cancer is provocative. For example, none of the seven MSH6 mutation carriers who developed breast cancer exhibited MSI in their tumors, whereas about half of the MSH2 and MLH1 mutation carriers did. In an overall analysis, no difference was seen in the age of mutation carriers and non-carriers or controls when diagnosed with breast cancer, but patients with breast cancers showing MSI or loss of MMR by IHC were statistically significantly younger.

So does LS lead to an increased incidence of breast cancer or younger age at diagnosis, or not? The numbers of participants remain too small to provide a definitive answer, but this retrospective study certainly suggests that, for the breast cancers that show MSI, their DNA repair defects contribute to their progression. However, there is no evidence in this cohort that MSI affects other aspects of the cancer phenotype, such as molecular pathology, stage, or outcome. Perhaps germline MSH6 mutations, relatively over-represented here in breast cancer cases compared with other LS-associated tumors, lead to breast cancer risks in the absence of high-level MSI through non-canonical mechanisms. To address such fascinating mechanistic questions, as well as more practical implications regarding the role of LS in breast cancer incidence and age at diagnosis, will require much larger studies. However, this study, together with others in the literature, does support a biologic role for LSassociated MSI in breast cancer progression. Since most patients with LS develop breast cancer after the age of 50, population-based breast cancer screening programs, including mammography, appear adequate for LS mutation carriers. A clear practical implication given the high specificity but modest sensitivity for MSI/IHC testing of breast cancer tumor tissue is that molecular phenotyping may be useful in the management and genetic testing of certain families when colorectal cancer or endometrial cancer tissue samples are unavailable. Finally, as 'universal' testing of all colorectal and endometrial cancers for MSI, independent of family history, becomes more standard [15], a similar approach in breast cancer will be a developing question. Ultimately, to determine whether breast cancer is a component of LS and, more importantly, whether MSI has prognostic or predictive value in breast cancer management, will require larger, population-based prospective studies.

\section{Abbreviations}

IHC, immunohistochemistry; LS, Lynch syndrome; MSI, microsatellite instability; MMR, mismatch repair.

Competing interests

The author declares that he has no competing interests.

Published: 22 August 2012

\section{References}

1. Lotsari JE, Gylling A, Abdel-Rahman WM, Nieminen TT, Aittomaki K, Friman M, Pitkanen R, Aarnio M, Jarvinen HJ, Mecklin JP, Kuopio T, Peltomaki P: Breast carcinoma and Lynch syndrome: molecular analysis of tumors arising in mutation carriers, non-carriers, and sporadic cases. Breast Cancer Res 2012, 14:R90.

2. Hanahan D, Weinberg RA: Hallmarks of cancer: the next generation. Cell 2011, 144:646-674.

3. Bodmer W, Bielas $J H$, Beckman RA: Genetic instability is not a requirement for tumor development. Cancer Res 2008, 68:3558-3560.

4. Loeb LA, Bielas JH, Beckman RA: Cancers exhibit a mutator phenotype: clinical implications. Cancer Res 2008, 68:3551-3557.

5. Lynch HT, de la Chapelle A: Hereditary colorectal cancer. N Engl J Med 2003, 348:919-932.

6. Hampel H, Frankel WL, Martin E, Arnold M, Khanduja K, Kuebler P, Clendenning M, Sotamaa K, Prior T, Westman JA, Panescu J, Fix D, Lockman J, LaJeunesse J, Comeras I, de la Chapelle A: Feasibility of screening for Lynch syndrome among patients with colorectal cancer. J Clin Oncol 2008, 26:5783-5788.

7. Ford JM, Whittemore AS: Predicting and preventing hereditary colorectal cancer. JAMA 2006, 296:1521-1523.

8. Lynch HT, Watson P, Kriegler M, Lynch JF, Lanspa SJ, Marcus J, SmyrkT, Fitzgibbons RJ Jr., Cristofaro G: Differential diagnosis of hereditary nonpolyposis colorectal cancer (Lynch syndrome I and Lynch syndrome II). Dis Colon Rectum 1988, 31:372-377.

9. Vasen HF, Morreau H, Nortier JW: Is breast cancer part of the tumor spectrum of hereditary nonpolyposis colorectal cancer? Am J Hum Genet 2001, 68:1533-1535.

10. Umar A, Boland CR, Terdiman JP, Syngal S, de la Chapelle A, Ruschoff J, Fishel R, Lindor NM, Burgart LJ, Hamelin R, Hamilton SR, Hiatt RA, Jass J, Lindblom A Lynch HT, Peltomaki P, Ramsey SD, Rodriguez-Bigas MA, Vasen HF, Hawk ET, Barrett JC, Freedman AN, Srivastava S: Revised Bethesda Guidelines for 
hereditary nonpolyposis colorectal cancer (Lynch syndrome) and microsatellite instability. J Nat/ Cancer Inst 2004, 96:261-268.

11. Adem C, Soderberg CL, Cunningham JM, Reynolds C, Sebo TJ, Thibodeau SN, Hartmann LC, Jenkins RB: Microsatellite instability in hereditary and sporadic breast cancers. Int J Cancer 2003, 107:580-582.

12. Buerki N, Gautier L, Kovac M, Marra G, Buser M, Mueller H, Heinimann K: Evidence for breast cancer as an integral part of Lynch syndrome. Genes Chromosomes Cancer 2012, 51:83-91.

13. Walsh MD, Buchanan DD, Cummings MC, Pearson SA, Arnold ST, Clendenning M, Walters R, McKeone DM, Spurdle AB, Hopper JL, Jenkins MA, Phillips KD, Suthers GK, George J, Goldblatt J, Muir A, Tucker K, Pelzer E, Gattas MR, Woodall S, Parry S, Macrae FA, Haile RW, Baron JA, Potter JD, Le Marchand L, Bapat B, Thibodeau SN, Lindor NM, McGuckin MA, Young JP: Lynch syndrome-associated breast cancers: clinicopathologic characteristics of a case series from the colon cancer family registry. Clin Cancer Res 2010, 16:2214-2224
14. Win AK, Young JP, Lindor NM, Tucker KM, Ahnen DJ, Young GP, Buchanan DD, Clendenning M, Giles GG, Winship I, Macrae FA, Goldblatt J, Southey MC, Arnold J, Thibodeau SN, Gunawardena SR, Bapat B, Baron JA, Casey G, Gallinger S, Le Marchand L, Newcomb PA, Haile RW, Hopper JL, Jenkins MA: Colorectal and other cancer risks for carriers and noncarriers from families with a DNA mismatch repair gene mutation: a prospective cohort study. J Clin Oncol 2012, 30:958-964.

15. Ladabaum U, Wang G, Terdiman J, Blanco A, Kuppermann M, Boland CR, Ford J, Elkin E, Phillips KA: Strategies to identify the Lynch syndrome among patients with colorectal cancer: a cost-effectiveness analysis. Ann Intern Med 2011, 155:69-79.

doi:10.1186/bcr3241

Cite this article as: Ford JM: Is breast cancer a part of Lynch syndrome? Breast Cancer Research 2012, 14:110. 